\title{
Filler and additive effects on partial discharge degradation of PET films used in PV devices
}

\author{
Rong Tang ${ }^{a}$, John J. Liggat ${ }^{a^{*}}$, Wah H. Siew ${ }^{b}$ \\ ${ }^{a}$ WestCHEM, Department of Pure and Applied Chemistry, University of Strathclyde, Glasgow, G1 1XL, \\ Scotland, United Kingdom. \\ ${ }^{b}$ Department of Electronic \& Electrical Engineering, University of Strathclyde, Glasgow G1 1XW, \\ Scotland, United Kingdom.
}

\begin{abstract}
A series of poly(ethylene terephthalate) (PET) films with different additives were subjected to identical electrical stresses to investigate their partial discharge (PD) degradation behaviour. Fourier transform infrared spectroscopy (FTIR), scanning electron microscopy (SEM) and Xray photoelectron spectroscopy (XPS) were used to study the surface chemistry changes of the degraded samples. The filled samples showed markedly better PD resistance and lifetime compared to the unfilled PET. A filler 'pile-up' effect has been directly observed for the filled samples and is proposed as the mechanism underlying the enhanced stability. PDinduced breakdown results also revealed that $\mathrm{TiO}_{2}$ filled PET has a superior PD lifetime to $\mathrm{BaSO}_{4}$ filled PET, which could be attributed to both the higher permittivity of the $\mathrm{TiO}_{2}$ fillers and the voids that are created around the $\mathrm{BaSO}_{4}$ particles during the film orientation process. Further improvements to PD resistance and PD lifetime, through the reduction of surface oxidation, are observed for a $\mathrm{BaSO}_{4}$-filled sample additionally containing the UV stabilizer Tinuvin 1577.
\end{abstract}

Key words: poly(ethylene terephthalate), photovoltaic, partial discharge, fillers, UV stabilizer.

"CORRESPONDING AUTHOR FOOTNOTE. Ph: $+44 \quad(0) 1415484351$ email:
j.j.liggat@strath.ac.uk




\section{Introduction}

In typical photovoltaic (PV) modules, a poly(ethylene terephthalate) (PET) film (normally 250 $\mu \mathrm{m}$ thick) is usually used as the core layer of the PV backsheet that insulates the module and provides mechanical stability due to its outstanding insulation and mechanical properties. During serving periods, the backsheet materials are potentially subjected to voltages as high as $1000 \mathrm{~V}$, sufficiently high to initiate partial discharge (PD) in the backsheet due to pollutants and moisture on the backsheet surface [1]. PD is defined as 'a localized electrical discharge that only partially bridges the insulation' [2], and, as a result, in most cases PD does not cause immediate system failure but degrades the insulation over time at a relatively slow rate. Energetic ion bombardment, excited molecules and high local temperature generated by discharges will chemically and physically degrade and erode the material, ultimately leading to dielectric breakdown if no remedy is taken [3]. This undoubtedly poses a threat to the electrical load of the PV module as well as the safety of people who work with the module. Furthermore, trends are moving to thinner and lighter PV modules including the backsheets, which will be particularly challenging for the safe electrical operation of the module since the backsheets will be subjected to a higher electric field. The PD behaviour of the whole backsheet depends greatly on the PET layer and, therefore, a comprehensive understanding of PD-induced degradation and breakdown of PET films is essential.

The chemistry of electrical discharge-induced degradation of PET has been extensively studied using a number of surface analytical techniques such as ATR-FTIR, XPS, contact angle and atomic force microscopy (AFM) [4-6]. Molecular chain scission was identified due to the bombardment of energetic electrons and ions from electrical discharge. Surface oxidation has been confirmed as oxygen-containing polar groups such as carbonyl, aldehyde and carboxylic acid were incorporated onto the sample surface, leading to the increase of hydrophilicity of the sample. The physical erosion effect has been also directly observed from SEM and AFM micrographs. From the electrical engineering aspect, it was reported that thicker PET samples are more prone to suffering internal PD degradation than thin ones when they are subjected to identical electric field since voids whose size are big enough to initiate a local dielectric breakdown are more likely to exist in a thicker sample [7].

As mentioned before, long-term PD degradation can lead to final dielectric breakdown of insulation materials. Since PV modules are expected to perform for at least 25 years under harsh environments, and given that detecting PDs with small magnitude ( $\sim \mathrm{pC})$ is typically difficult, it is vital to explore methods to enhance the PD resistance as well as PD lifetime of PET films to ensure the safe electrical operation of PV modules. Using a thicker core layer of PET film is the easiest and most effective way to increase the PD resistance for the 
backsheet but this apparently contradicts the developing trends of PV industry by increasing the overall costs of the module. Fillers and performance additives are commonly utilized to modify and improve the mechanical, physical and electrical properties of polymers or their aesthetic appearance. PD resistance can be significantly enhanced by such additives. For example, Kozako et al. [8] report increased resistance with polyamide (PA) as the basic resin and layered silicate as a nano-filler. Subsequently, much work has been done to investigate the inorganic filler effect on PD as well as electrical treeing resistance of epoxy resin and polyimide [9-15]. The fillers mainly used were layered silicate, $\mathrm{TiO}_{2}, \mathrm{SiO}_{2}$ and $\mathrm{Al}_{2} \mathrm{O}_{3}$. All the results have shown that even with a small amount of filler, the PD resistance of the polymer composites can be considerably improved compared to the neat resin. However, the influence of inorganic fillers on PD degradation and resistance of PET films has been seldom investigated. Backsheets are usually white because of the higher reflectance and efficiency. $\mathrm{BaSO}_{4}$ and $\mathrm{TiO}_{2}$ are two common fillers used in commercial PET films to increase the product's whiteness due to low cost and high refractive index, respectively. UV stabilizers are often used in the outer layered PET film of backsheets to provide UV stability. How these fillers and UV stabilizers would affect the PD degradation of PET films in PV devices is still unclear. In this work, four kinds of PET films filled with different additives namely, pure PET, PET filled with $\mathrm{TiO}_{2}$ and PET filled with $\mathrm{BaSO}_{4}$ (with and without UV stabilizer) were subjected to a surface partial discharge to study the filler and additive effects on PD degradation and breakdown behaviour of PET films.

\section{Experimental}

\subsection{Samples}

Four categories of biaxially oriented, semicrystalline PET films filled with different fillers kindly provided by DuPont Teijin Films were used to investigate the effect of fillers on PD degradation and breakdown of PET films. All the samples have identical thickness of $50 \mu \mathrm{m}$. Each sample category is described below:

1. Mylar A, PET used as a reference (PET).

2. PET filled with $18 \% \mathrm{BaSO}_{4}\left(\mathrm{PET}-\mathrm{BaSO}_{4}\right)$.

3. PET filled with $18 \% \mathrm{BaSO}_{4}$ and containing $1.0 \%$ Tinuvin 1577 UV stabilizer (PET$\left.\mathrm{BaSO}_{4}-\mathrm{UV}\right)$.

4. PET filled with $13 \% \mathrm{TiO}_{2}\left(\mathrm{PET}-\mathrm{TiO}_{2}\right)$. 


\subsection{Experimental set-up of partial discharge and breakdown tests}

Partial discharge degradation and breakdown experiments were conducted using the IEC (b) electrode system according to IEC 60343. The electrode system consists of a rod and a plane stainless-steel electrode where the rod electrode has an end curvature of $1 \mathrm{~mm}$ radius (Figure 1). The whole system was enclosed in a PMMA tube in which silica gel was used to keep the relative humidity as low as possible. Temperature, $20 \pm 2^{\circ} \mathrm{C}$, was not specifically controlled during experiments. The voltage frequency is $50 \mathrm{~Hz}$ for all tests. For multiplesamples PD test, a set of high voltage rod electrodes (as many as seven) were used, to enable PD experiments to be run with up to seven samples in parallel.

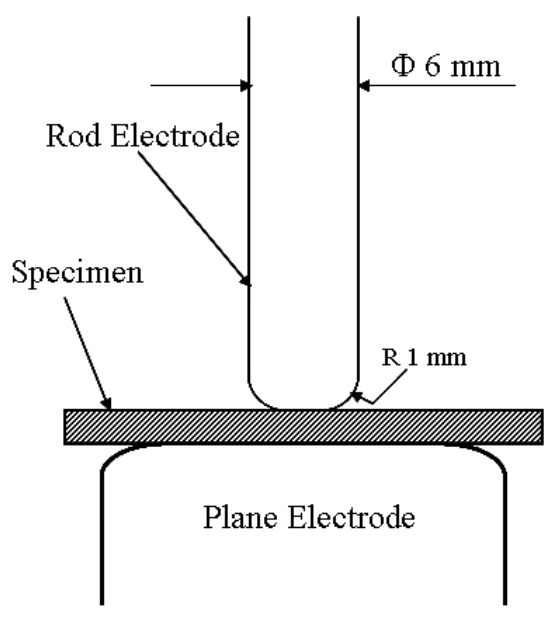

Figure 1: Schematic diagram of IEC (b) electrode system

Two sets of experiments were carried out to investigate the additives effect on PD degradation and breakdown behaviours of the PET films.

\subsubsection{Experimental set-up for PD tests}

Sample stacks comprising five sheets for each sample category with identical thickness (250 $\mu \mathrm{m}$ ) were subjected to a $50 \mathrm{~Hz}$ AC high voltage of $3 \mathrm{kV}$ for 12, 24 and 48 hours. After PD exposure only the upper side of the top sheet showed any visible sign of damage and only this surface was subjected to further analysis. 


\subsubsection{Experimental set-up for PD-lifetime test}

Single sheets of samples of each category were subjected to a $50 \mathrm{~Hz}$ AC high voltage of 3 $\mathrm{kV}$ until the sample broke down due to PD erosion. For each sample category, ten samples were tested and the average values of the PD lifetime of each category were calculated.

\section{$2.3 \quad$ FTIR analysis}

FTIR spectra of samples in this project were collected using an Agilent 5500 Series ATRFTIR instrument equipped with a single reflection diamond. The spectral range of the instrument is $650-4700 \mathrm{~cm}^{-1}$, with a resolution of $8 \mathrm{~cm}^{-1} .128$ background and sample scans were accumulated for each spectrum. For each sample, five spectra were collected and then averaged using Panorama Pro® software from LabCognition $\mathrm{GmbH}$ (https://www.labcognition.com/en/Panorama.html).

\section{$2.4 \quad$ XPS analysis}

XPS measurements were carried out at the National EPSRC XPS Users' Service (NEXUS) in Newcastle University using a Kratos Analytical AXIS Nova x-ray photoelectron spectrometer. A survey scan was acquired for each sample followed by higher resolution scans of $C$ 1s and O 1s. A monochromatic Al Ka X-ray with energy of $1486.6 \mathrm{eV}$ was applied to irradiate samples. The power of the $\mathrm{x}$-ray gun is $225 \mathrm{~W}$. Pass energy for XPS survey and higher resolution scan were $160 \mathrm{eV}$ and $20 \mathrm{eV}$, respectively.

\subsection{Surface profilometry}

The erosion depths of treated samples were measured using a Veeco Dektak 6M stylus profilometer. The profilometer is equipped with a diamond stylus with a radius of $12.5 \mu \mathrm{m}$. During each measurement, the stylus moves radially across the sample surface and the vertical motion of the stylus is measured. The starting point of the stylus for each scan was selected as the centre of the sample. The scan length and scan speed were set to $7000 \mu \mathrm{m}$ and $100 \mu \mathrm{m} \mathrm{s}^{-1}$, respectively. The erosion depth is defined as the height difference, along the stylus path, between the lowest point at the erosion valley and the highest point at the unexposed area. 


\section{$3 \quad$ Results and discussions}

\subsection{PD lifetime and erosion depth analyses}

PD lifetime experiments were firstly conducted for each kind of sample to compare the high voltage endurance of samples under the same conditions. Further PD tests (5x50 $\mu \mathrm{m}$ sheets) were then carried out to analyse the PD resistance of each kind of sample with the top layer of each stack tested for erosion depth and surface chemistry analysis. PD lifetime and erosion depth data are shown in Table 1. The PD lifetimes of the samples are in the ranking of PET-BaSO 4 -UV $>$ PET-TiO $2>$ PET-BaSO 4 P PET. Similarly, from the erosion depth of each sample, it is clear that pure PET without any additive eroded fastest under PD while the samples filled with inorganic particles $\left(\mathrm{BaSO}_{4}\right.$ and $\left.\mathrm{TiO}_{2}\right)$ have much better $\mathrm{PD}$ resistance.

\begin{tabular}{ccccc}
\hline Samples & $\begin{array}{c}\text { PD lifetime I } \\
\text { mins (3kV) }\end{array}$ & $\begin{array}{c}\text { Erosion depth I } \\
\mathbf{n m ~ ( 1 2 h r s )}\end{array}$ & $\begin{array}{c}\text { Erosion depth I } \\
\mathbf{n m} \text { (24hrs) }\end{array}$ & $\begin{array}{c}\text { Erosion depth I } \\
\mathbf{n m} \text { (48hrs) }\end{array}$ \\
\hline PET & $109 \pm 46$ & $3021 \pm 46$ & $5583 \pm 88$ & $11062 \pm 389$ \\
PET-BaSO $_{4}$ & $163 \pm 13$ & $1879 \pm 78$ & $3512 \pm 200$ & $5965 \pm 222$ \\
PET-TiO $_{2}$ & $194 \pm 20$ & $2032 \pm 56$ & $3551 \pm 157$ & $5766 \pm 208$ \\
PET-BaSO $_{4}$-UV & $212 \pm 12$ & $1826 \pm 185$ & $3160 \pm 159$ & $5689 \pm 226$ \\
\hline
\end{tabular}

Table 1: PD lifetimes and erosion depths of samples with different additives (as an average of 10 samples and showing standard deviation)

\subsection{Surface chemistry analyses}

PET

According to Liang [16], Grime [17] and Chen [18], the main IR absorption bands of PET can be assigned as follows, $723 \mathrm{~cm}^{-1}$ to the $\mathrm{C}-\mathrm{H}$ out-of-plane deformation, $1095 \mathrm{~cm}^{-1}$ and 1120 $\mathrm{cm}^{-1}$ due to the $\mathrm{C}-\mathrm{O}$ stretching in the amorphous and crystalline regions respectively, 1245 $\mathrm{cm}^{-1}$ to the $\mathrm{O}=\mathrm{C}-\mathrm{O}$ stretching in the ester group, $1340-1470 \mathrm{~cm}^{-1}$ to the wagging and bending of the $\mathrm{CH}_{2}, 1717 \mathrm{~cm}^{-1}$ to the carbonyl group stretching and $2970 \mathrm{~cm}^{-1}$ to the $\mathrm{CH}_{2}$ stretching. 
Figure 2 represents the comparison of carbonyl region of the untreated and PD exposed PET samples, from which one can see that the carbonyl band is broader to low wavenumbers for the PET film that received PD degradation. This broadening is consistent with the production of carboxylic acid and aldehydic structures [19]. A new wide band appeared in the region of $3100-3650 \mathrm{~cm}^{-1}$ after the PET samples were PD exposed (figure not shown in here). This new band can be assigned to -OH group stretching and carboxylic acids.

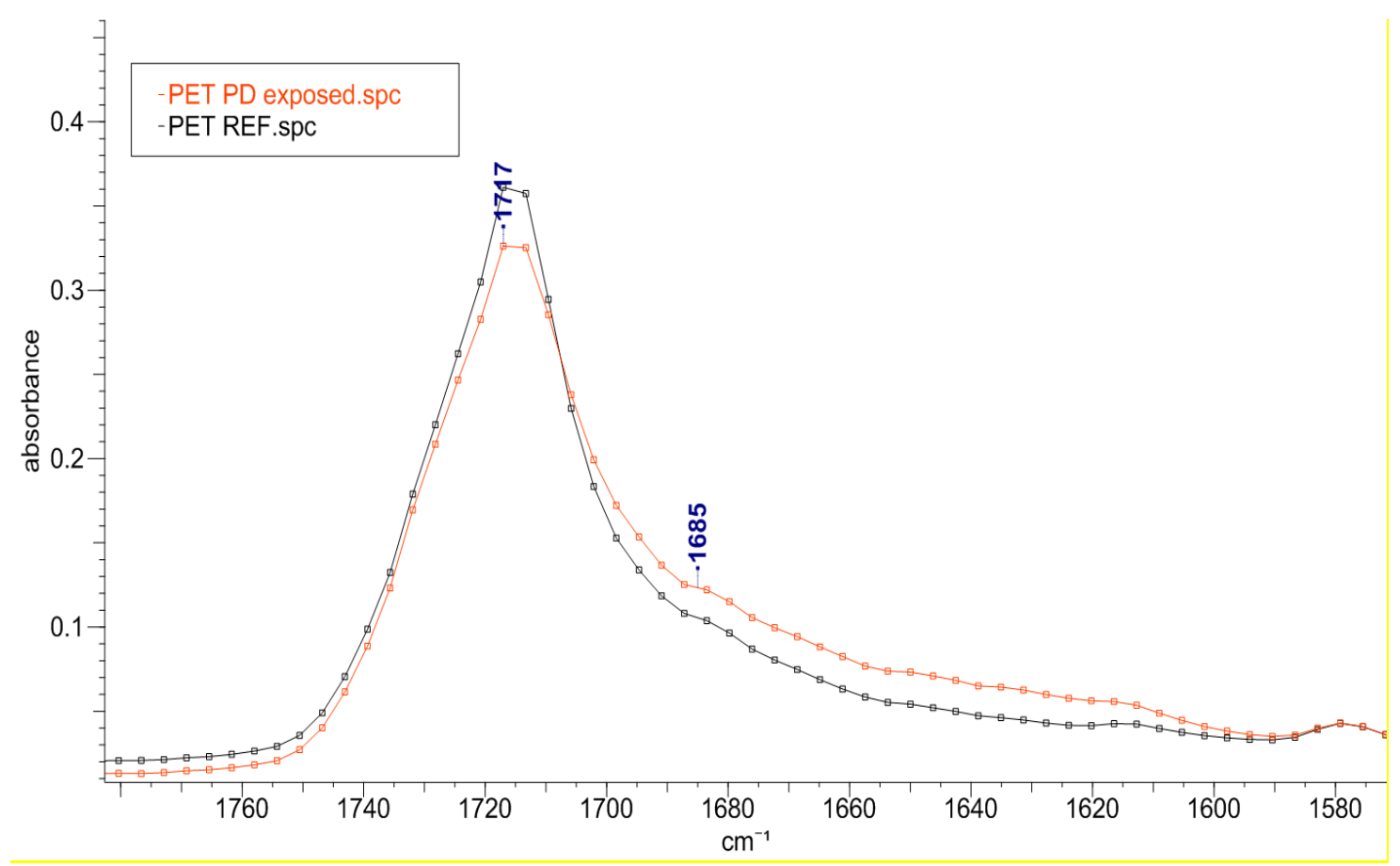

Figure 2: Overlaid FTIR carbonyl absorption bands of PET, untreated and PD exposed

XPS survey scans were carried out to study the surface chemistry changes quantitatively For the untreated PET samples, only carbon and oxygen were detected due to the chemical structure of PET. After PD degradation new peaks are present at 401.77 and $540.77 \mathrm{eV}$. These have been attributed to $\mathrm{N} 1 \mathrm{~s}$ and $\mathrm{Sb} 3 \mathrm{~d}$, respectively. The presence of nitrogen atoms confirms that nitrogen-containing compounds such as amides and amines could be generated after the samples reacted with air discharge $[4,20]$. On the other hand, the presence of antimony could be explained by the so-called 'corona etching' effect - the PET resin degrades away and leaves behind on the surface the antimony-containing species, most likely $\mathrm{Sb}_{2} \mathrm{O}_{3}$, which is a common catalyst used in the production of PET. For PD exposed samples, the ratio of $\mathrm{C} 1 \mathrm{~s}: \mathrm{O}$ 1s decreased from 3.09:1 in the as-received sample to around 1.96:1, indicative of surface oxidation (Table 2). 


\begin{tabular}{|c|c|c|c|}
\hline Samples & O 1s (\%) & C 1s (\%) & C/O ratio \\
\hline Untreated & $24.44 \pm 0.11$ & $75.56 \pm 0.11$ & 3.09 \\
\hline PD exposed & $33.46 \pm 0.40$ & $65.72 \pm 1.07$ & 1.96 \\
\hline
\end{tabular}

Table 2: XPS survey scan results of unfilled PET, both untreated and PD exposed

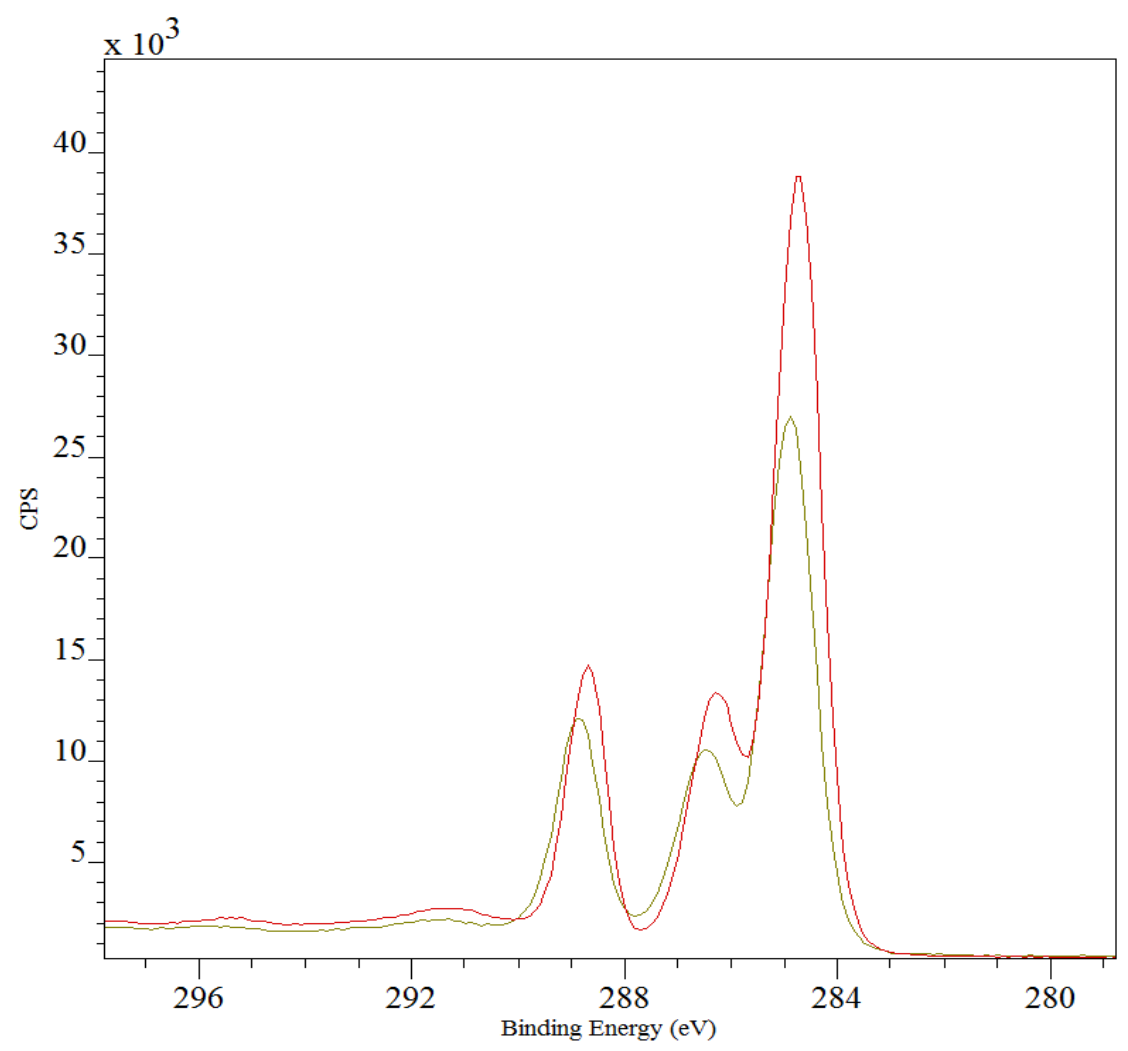

Figure 3: Overlaid C 1s spectra of PET, untreated (red) and PD exposed (green)

More details about PD degradation mechanisms on PET films can be obtained by looking at higher resolution scans of $\mathrm{C}$ 1s of the samples (Figure 3). According to the literature, the three peaks in the $\mathrm{C} 1 \mathrm{~s}$ scan of the untreated PET (red), which are at $284.80 \mathrm{eV}, 286.41 \mathrm{eV}$ and $288.78 \mathrm{eV}$ are attributed to the carbon atom (underlined) in $\underline{\mathrm{C}}-(\mathrm{C}, \mathrm{H}), \underline{\mathrm{C}}-\mathrm{O}$ and $\mathrm{O}=\underline{\mathrm{C}}-\mathrm{O}$ in PET, respectively [4]. Note that the reduction in peak heights for the PD exposed sample, and the slight $\mathrm{x}$-axis shift are both artefacts of the XPS process.

\section{PET-BaSO 4 and PET- $\mathrm{BaSO}_{4}-\mathrm{UV}$}

The comparison of the ATR-FTIR spectra of PET and PET-BaSO 4 is illustrated in Figure 4. Only spectral data from the region between 920 and $1360 \mathrm{~cm}^{-1}$ are shown since the only 
differences in these two spectra lie in this region. Compared to the IR spectrum of pure PET, four additional absorption peaks can be observed at 1188, 1120, 1072 and $983 \mathrm{~cm}^{-1}$ for the PET-BaSO 4 spectrum. The three peaks at 1188,1120 and $1072 \mathrm{~cm}^{-1}$ are attributed to the S$\mathrm{O}$ stretching of the inorganic filler $\mathrm{BaSO}_{4}$, while the peak at $983 \mathrm{~cm}^{-1}$ can be attributed to the symmetrical vibration of $\mathrm{SO}_{4}{ }^{2-}$ [21]. No other absorption peak shifts or changes can be observed for these two spectra. The IR spectra of PET-BaSO 4 and PET-BaSO $4-U V$ are almost the same apart from an additional peak at $1530 \mathrm{~cm}^{-1}$ that is observed for $\mathrm{PET}-\mathrm{BaSO}_{4}$ UV, and is due to the in-plane ring vibration of the triazine ring system in the Tinuvin 1577 UV stabilizer [22].

ATR-FTIR spectra of PET-BaSO 4 subjected to PD exposure for 0, 12, 24 and 48 hours are illustrated in Figure 5; only spectra of $\mathrm{PET}-\mathrm{BaSO}_{4}$ are shown here due to the extremely high

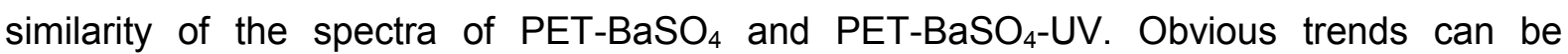
observed from the figure: the intensity of the band at $1245 \mathrm{~cm}^{-1}$, which is due to the $=\mathrm{C}-\mathrm{O}$ stretching in the ester group [14], decreased as the PD exposure time increased. On the other hand, the intensities of the main characteristic bands of $\mathrm{BaSO}_{4}$ at 1188,1072 and 983 $\mathrm{cm}^{-1}$ increased. This is direct evidence of the accumulation process of the fillers $\mathrm{BaSO}_{4}$ on the sample surface as PD exposure time increases. This so called 'filler pile-up' effect has been well discussed in the literature [6-8]. Since the PD resistance of the inorganic fillers is much higher than that of the polymer, the originally embedded fillers will remain on the sample surface while the polymer is degrading due to the PD erosion. 


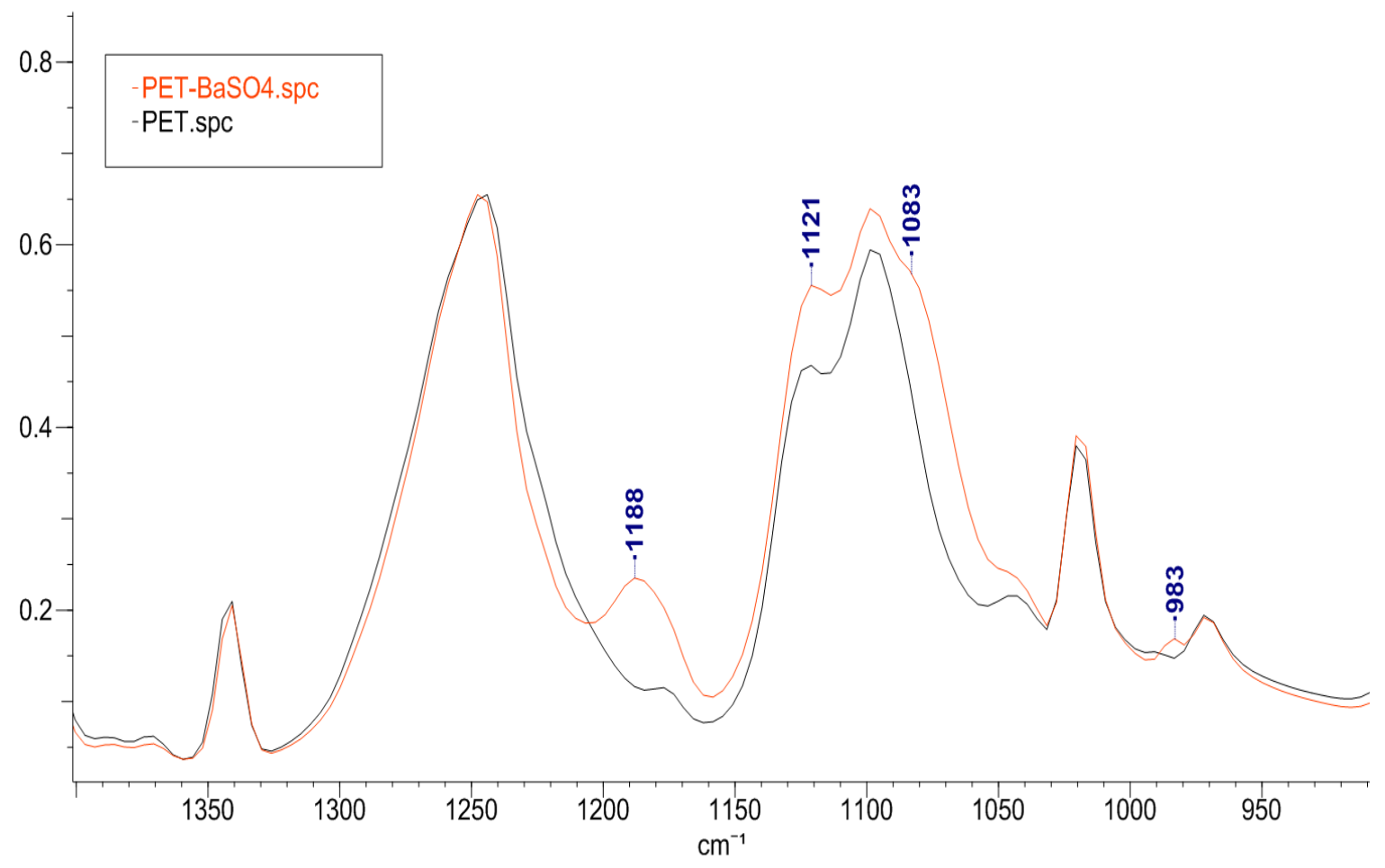

Figure 4: Overlaid ATR-FTIR spectra of PET and PET-BaSO 4

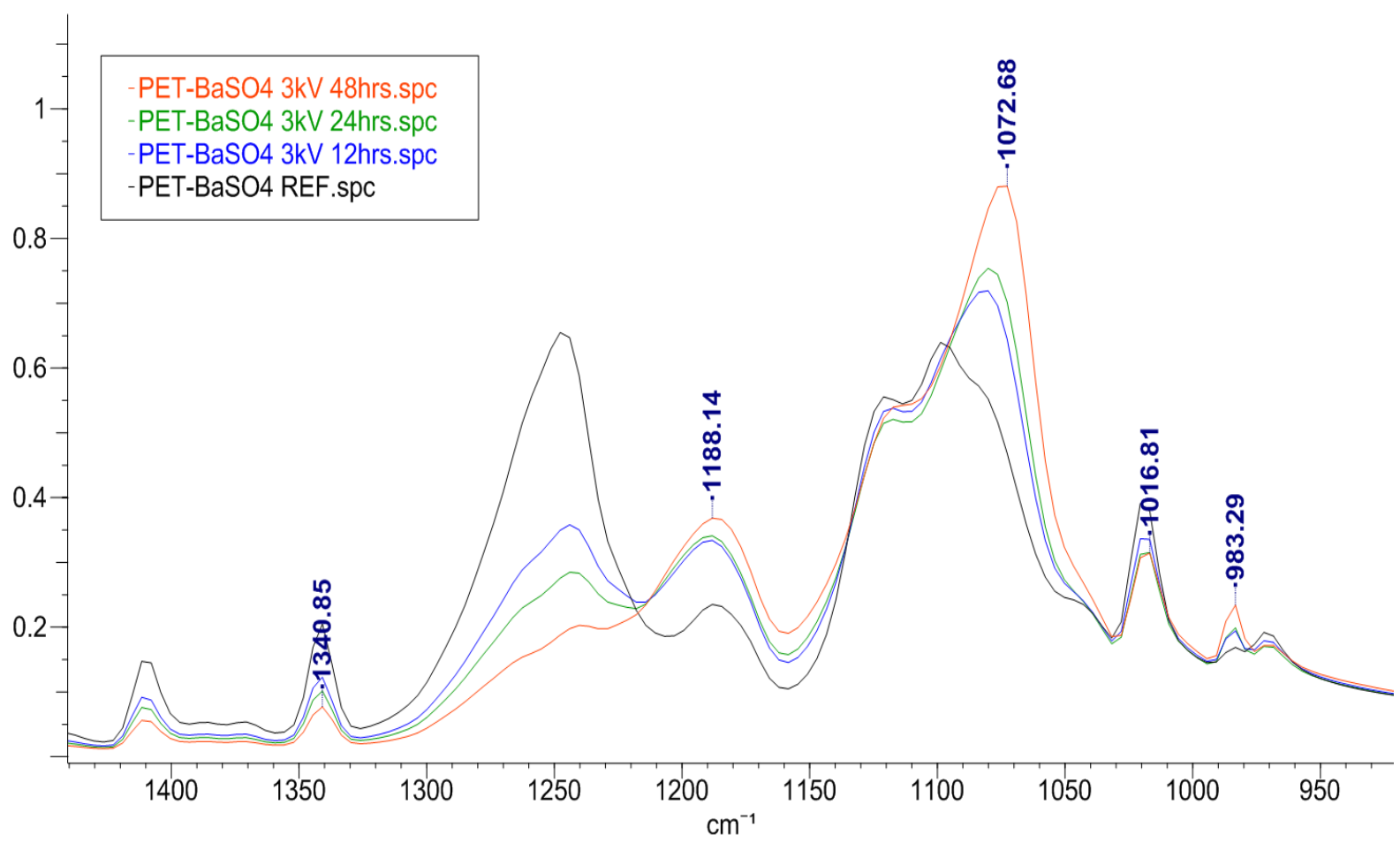

Figure 5: Overlaid ATR-FTIR spectra of PET-BaSO 4 subjected to PD for $0,12,24$ and $48 \mathrm{hrs}$ 
No absorption peak shifts can be observed in either $\mathrm{C}$ 1s or $\mathrm{O}$ 1s spectra (spectra not shown in here) for unexposed PET-BaSO 4 and PET-BaSO ${ }_{4}-\mathrm{UV}$. It is also worth pointing out that only elements of carbon and oxygen are present, i.e., barium or sulphur cannot be detected in the survey for the untreated samples of PET-BaSO ${ }_{4}$ and PET-BaSO ${ }_{4}-\mathrm{UV}$, possibly due to the short sampling depth of XPS (usually only a few $\mathrm{nm}$, which may not be sufficient to reach the inorganic fillers dispersed in the resin). The atomic concentrations of each element present on the surface of the two samples after PD exposure are listed in Table 3 (data for samples subjected to $3 \mathrm{kV}$ for 0,12 and 24 hours are present). From the results it can be seen more quantitatively how the filler $\mathrm{BaSO}_{4}$ accumulates on the PD treated sample surface. It is also seen that the surface concentrations of barium and sulphur are nearly identical for the two samples after exposure for both 12 and 24 hours. However, the

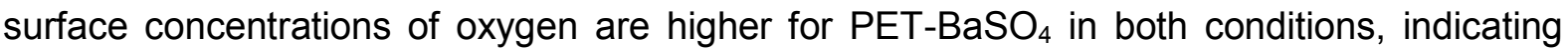
that surface oxidation is more severe for PET-BaSO 4 than PET-BaSO $\mathrm{PO}_{4} \mathrm{UV}$. This is probably due to the presence of the UV stabilizer in PET-BaSO 4 -UV which could hinder the oxidation and UV degradation caused by the PD. Tinuvin 1577 is a highly effective UV absorber designed to be effective in the top few $\mu \mathrm{m}$ of a polymer's surface, and has been demonstrated to stabilise surface chemistry at distances commensurate with the penetration depth of XPS [23].

\begin{tabular}{|c|c|c|c|c|c|}
\hline Samples & $01 \mathrm{~s} / \%$ & C 1s/\% & Ba 3d / \% & S 2p / \% & N1s / \% \\
\hline Untreated & $24.44 \pm 0.11$ & $75.56 \pm 0.11$ & 0 & 0 & 0 \\
\hline $\begin{array}{c}\text { PET-BaSO }_{4} \\
12 \mathrm{hrs}\end{array}$ & $41.89 \pm 0.45$ & $49.27 \pm 0.36$ & $4.53 \pm 0.21$ & $4.11 \pm 0.33$ & $0.21 \pm 0.07$ \\
\hline $\begin{array}{c}\text { PET-BaSO }_{4-} \\
\text { UV } 12 \mathrm{hrs}\end{array}$ & $39.81 \pm 0.54$ & $51.66 \pm 0.37$ & $4.30 \pm 0.19$ & $3.82 \pm 0.22$ & $0.40 \pm 0.11$ \\
\hline $\begin{array}{c}\text { PET-BaSO }_{4} \\
24 \mathrm{hrs}\end{array}$ & $46.40 \pm 0.78$ & $40.95 \pm 0.81$ & $6.77 \pm 0.54$ & $5.73 \pm 0.54$ & $0.16 \pm 0.13$ \\
\hline $\begin{array}{c}\text { PET-BaSO }_{4-} \\
\text { UV } 24 \mathrm{hrs}\end{array}$ & $43.84 \pm 0.67$ & $43.87 \pm 0.25$ & $6.51 \pm 0.30$ & $5.41 \pm 0.33$ & $0.38 \pm 0.13$ \\
\hline
\end{tabular}

Table 3: XPS survey results of PET-BaSO 4 and PET-BaSO $4-U V$

Overlaid $O$ 1s and $C$ 1s XPS spectra of the untreated and PD exposed PET-BaSO 4 are shown in Figure 6 . The peak fitting results of both the $O 1 \mathrm{~s}$ and $C 1 \mathrm{~s}$ spectra of PD-exposed 
PET-BaSO 4 are also shown in the figure. For the reason mentioned above, only spectra of PET-BaSO 4 are shown in here. In the $O$ 1s spectrum (left), one can see that the original doublet became one strong featureless peak at $531.5 \mathrm{eV}$ after PD treatment. For the $\mathrm{C}$ 1s spectrum (right), the intensities of all the carbon peaks decreased dramatically after PD exposure. It should be noted that for the post-PD exposure samples the spectra became broad. Shoulders in the lower binding energy regions can be observed for both spectra, suggesting the formation of new peaks. For the $O$ s spectrum, peak $B$, at $533.2 \mathrm{eV}$, is attributed to the oxygen atom $\underline{\mathrm{O}}-\mathrm{C}=\mathrm{O}$ in $\mathrm{PET}$, whose peak area is relatively small because of the presence of inorganic fillers and PET degradation. The biggest peak $\mathrm{A}$, at $531.6 \mathrm{eV}$, can be attributed to the oxygen atom $\mathrm{O}-\mathrm{C}=\underline{\mathrm{O}}$ in $\mathrm{PET}$ and, the oxygen atom of the $-\mathrm{SO}_{4}$ group in $\mathrm{BaSO}_{4}[24,25]$. Since these two peaks are highly superimposed, it is almost impossible to separate them. A new peak C, evident as a shoulder located at $530.2 \mathrm{eV}$, can be assigned to the presence of barium oxide, i.e., $\mathrm{BaO}$, which could be the decomposition product of $\mathrm{BaSO}_{4}$ when the temperature is as high as $1580^{\circ} \mathrm{C}$ [26]. According to T. Tanaka [3], even a tiny $\mathrm{PD}$ can raise the local temperature near the solid surface up to $1000^{\circ} \mathrm{C}$ for a very short period $(0.1 \mu \mathrm{s})$. It is not surprising, therefore, that $\mathrm{BaO}$ could be detected on the sample surface in this case. For the $\mathrm{C} 1 \mathrm{~s}$ spectrum, the three peaks at 284.8, 286.7 and $288.7 \mathrm{eV}$ are assigned to the PET carbon atoms $\underline{\mathrm{C}}-(\mathrm{C}, \mathrm{H}), \underline{\mathrm{C}}-\mathrm{O}$ and $\mathrm{O}=\underline{\mathrm{C}}-\mathrm{O}$, respectively. The relative area of peak $\mathrm{B}$ at $286.7 \mathrm{eV}$ increases a little after PD exposure; this could possibly be due to the adventitious carbon attached to the $\mathrm{BaSO}_{4}$ surface. The new peak $\mathrm{D}$ that appears at $288.0 \mathrm{eV}$ can be assigned to barium carbonate, $\mathrm{BaCO}_{3}$, since metal carbonates are usually observed on metal oxides ( $\mathrm{BaO}$ in this case) [27]. Further, another newly generated peak $\mathrm{E}$, evident as a shoulder at $283.5 \mathrm{eV}$, can be attributed to the formation of barium carbide, $\mathrm{BaC}_{2}$, which could be generated from barium oxide under the condition of local high temperature and electrical discharge. 

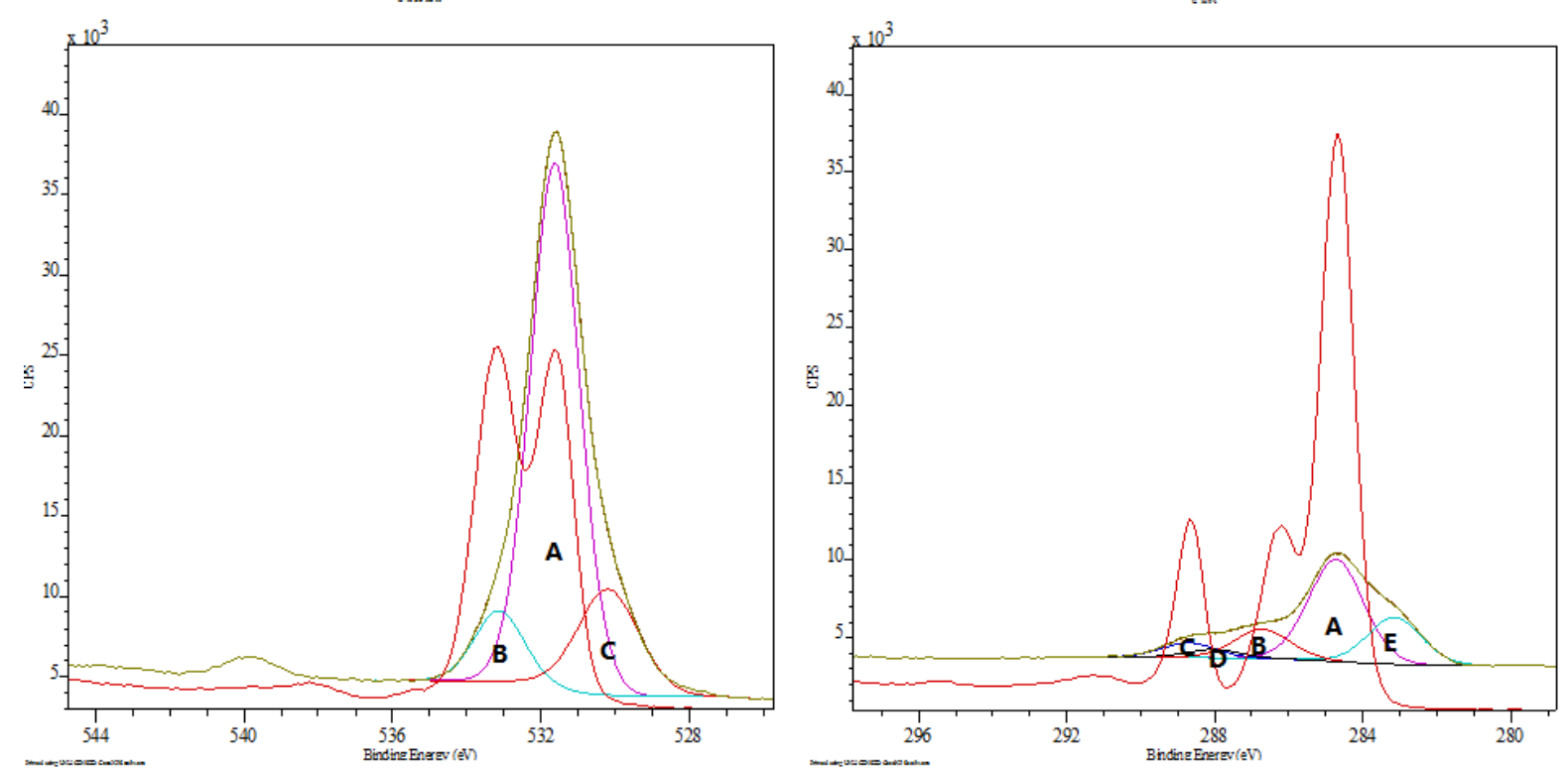

Figure 6: Overlaid O 1s (left) and C 1s (right) XPS spectra of PET-BaSO 4 before (red) and after (green) PD exposure (lettered curves)

\section{PET-TiO 2}

Figure 7 represents the overlaid ATR-FTIR spectra of PET and PET-TiO 2 . Only IR spectra between 650 and $940 \mathrm{~cm}^{-1}$ are shown here since the only differences between these two spectra lie in this region. A wide absorption band is observed in the wavenumber region lower than $800 \mathrm{~cm}^{-1}$ for $\mathrm{PET}-\mathrm{TiO}_{2}$, which can be assigned to the vibration of $\mathrm{Ti}-\mathrm{O}$ of the $\mathrm{TiO}_{2}$ fillers [28]. No other absorption peak shifts or changes can be observed for these two spectra. Fig. 8 shows the ATR-FTIR spectra of $\mathrm{PET}_{-\mathrm{TiO}_{2}}$ after receiving PD exposure for 0 , 12, 24 and 48 hours. It is clear that the characteristic absorption band of $\mathrm{TiO}_{2}$, located in the wavenumber region lower than $800 \mathrm{~cm}^{-1}$, increased as the PD exposure time increased, indicating the 'pile-up' phenomenon of the $\mathrm{TiO}_{2}$ fillers on the PD exposed samples, similar to that observed for PET-BaSO ${ }_{4}$ and PET-BaSO 4 -UV. 


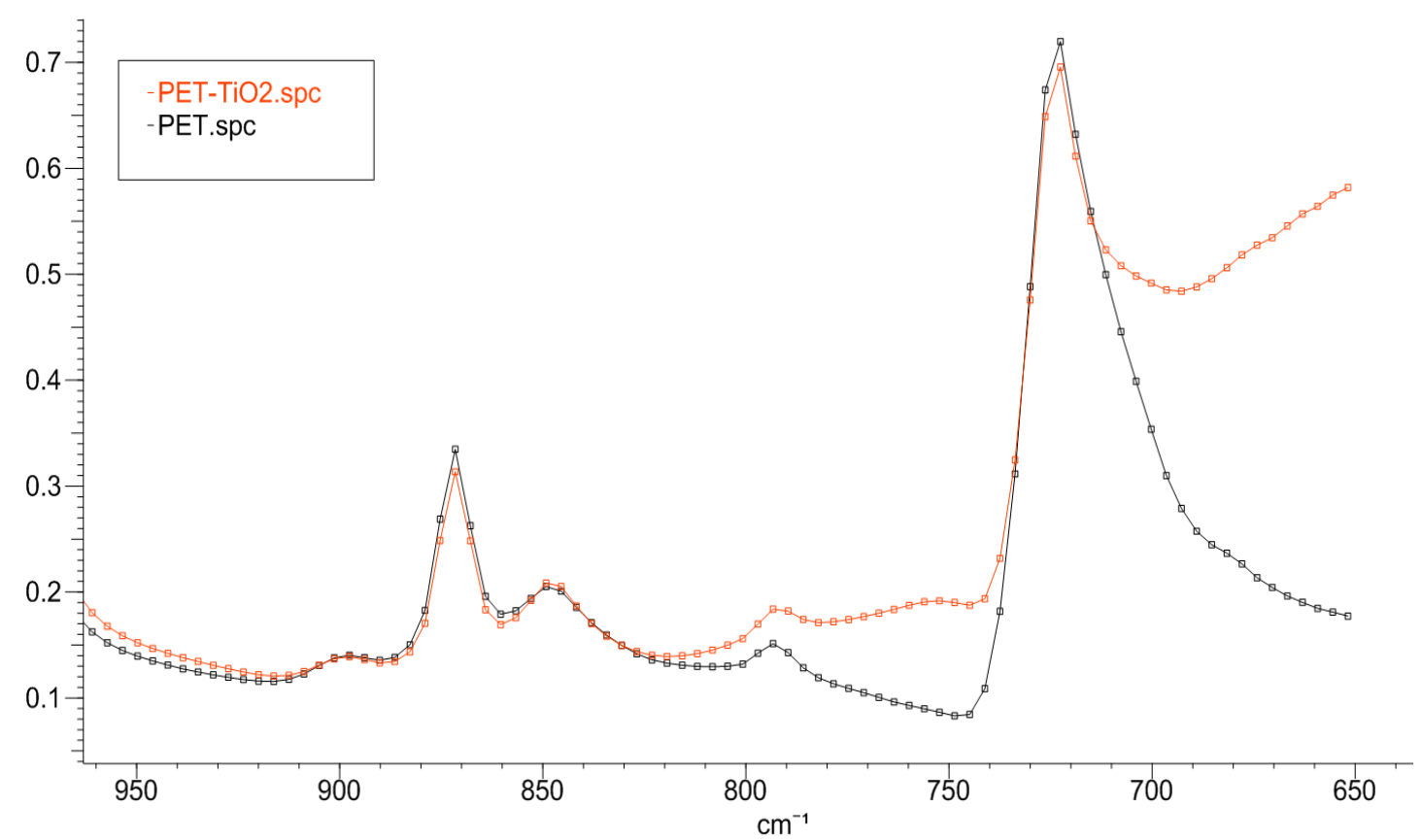

Figure 7: Overlaid ATR-FTIR spectra of PET and PET-TiO 2

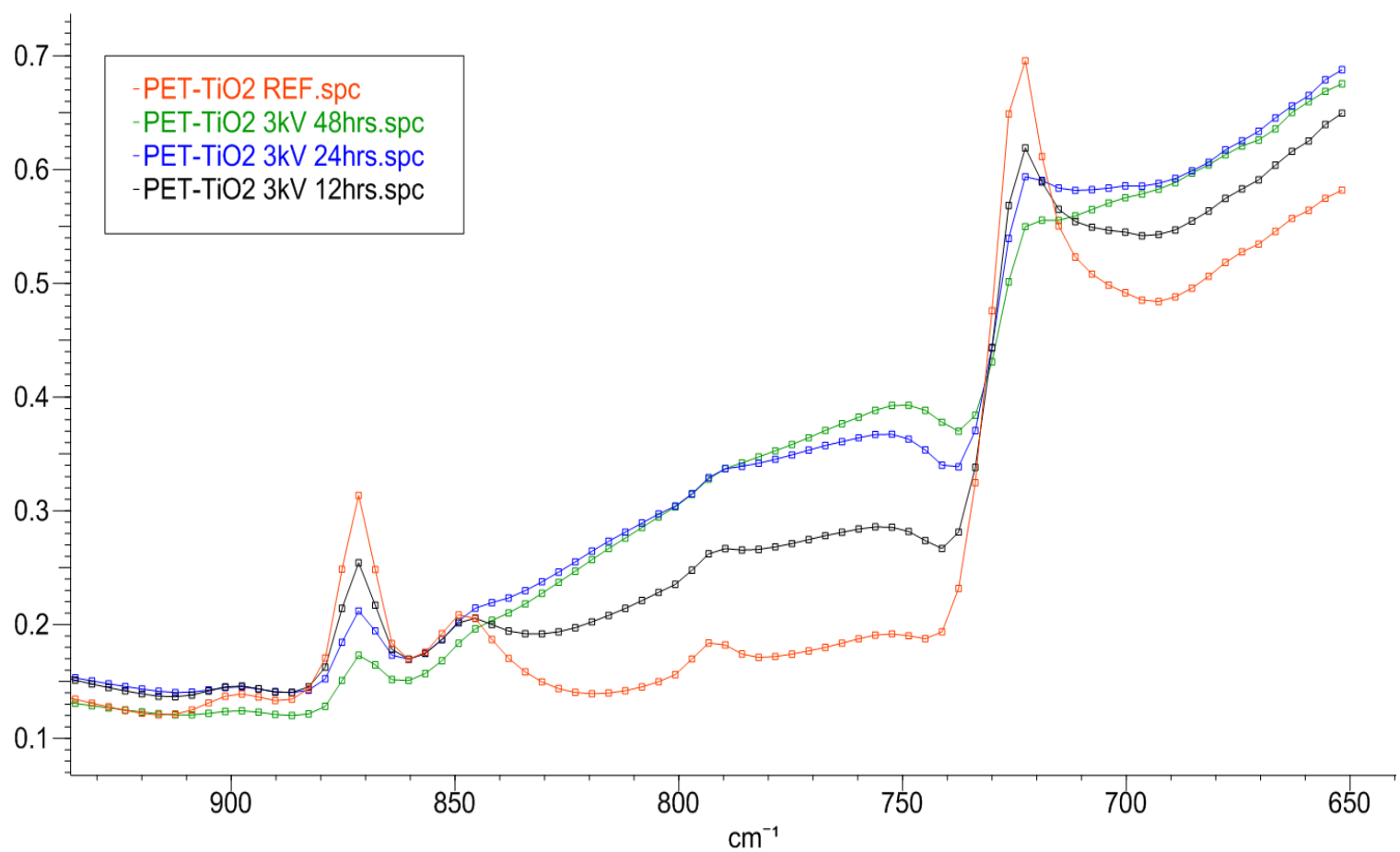

Figure 8: Overlaid ATR-FTIR spectra of PET-TiO 2 subjected to PD for $0,12,24$ and 48hrs

Similar to the case of PET-BaSO 4 and $\mathrm{PET}-\mathrm{BaSO}_{4}-\mathrm{UV}$, only carbon and oxygen are observed in the XPS survey of untreated PET-TiO 2 due to the short sampling depth of XPS. For the PD-exposed PET-TiO 2 , there are prominent absorption peaks at 458.7 and $464.6 \mathrm{eV}$ that are due to Ti $2 p$. In addition, a series of small peaks were observed in the region where 
binding energy $(\mathrm{BE})$ is lower than $200 \mathrm{eV}$. The small peaks are identified as Si 2p, Al 2p and P $2 p$ (Table 4). It is known that commercial $\mathrm{TiO}_{2}$ will always have a coating such as aluminosilicate, organosilane etc. to provide a UV protection or compatibilisation functionality [29], and elements such as phosphorus and sodium could be present on the surface of the aluminosilicate [30].

\begin{tabular}{|c|c|c|c|c|c|c|c|}
\hline Samples & O 1s & C 1s & N 1s & Si 2p & Al 2p & Ti 2p & P 2p \\
\hline Untreated & $\begin{array}{c}24.44 \pm \\
0.11\end{array}$ & $\begin{array}{c}75.56 \pm \\
0.11\end{array}$ & 0 & 0 & 0 & 0 & 0 \\
\hline $\begin{array}{c}\text { PET-TiO2 } \\
\text { 12hrs }\end{array}$ & 37.06 & 56.18 & 0.34 & 1.09 & 1.97 & 2.83 & 0.53 \\
\hline $\begin{array}{c}\text { PET-TiO2 } \\
\text { 24hrs }\end{array}$ & 44.21 & 44.58 & 0.37 & 1.99 & 3.04 & 4.96 & 0.85 \\
\hline
\end{tabular}

Table 4: XPS survey results of PET-TiO 2

Overlaid $\mathrm{O}$ 1s and $\mathrm{C}$ 1s XPS spectra of untreated and PD exposed PET-TiO 2 are illustrated in Fig. 9. Also shown are the peak fitting results of both the $O 1 \mathrm{~s}$ and $C$ is spectra of $P D$ exposed $\mathrm{PET}_{-} \mathrm{TiO}_{2}$.. One can see that in the $\mathrm{O}$ 1s spectrum (left), the original $\mathrm{O}$ 1s doublet of PET changes into one strong band and the peak position shifts from 531.5 to $532.0 \mathrm{eV}$ after the samples were PD exposed. Furthermore, a distinct new peak is now observed at $529.8 \mathrm{eV}$. For the $\mathrm{C} 1 \mathrm{~s}$ spectrum (right), it can be seen that the intensities of all the $\mathrm{C} 1 \mathrm{~s}$ peaks drop significantly after PD degradation due to the filler 'pile-up' effect. For the $O 1 \mathrm{~s}$ spectrum, the strongest band $\mathrm{A}$ whose peak position is at $532.0 \mathrm{eV}$ is considered to be the superimposition of the peak at $531.5 \mathrm{eV}$ due to the oxygen atom $\mathrm{O}-\mathrm{C}=\underline{\mathrm{O}}$ in $\mathrm{PET}$ and the peak at $532.0 \mathrm{eV}$ due to the presence of $\mathrm{OH}$ groups attached to the $\mathrm{TiO}_{2}$ filler surface. The peak $B$ is attributed to the oxygen atom $\underline{O}-\mathrm{C}=\mathrm{O}$ in PET. The distinct new peak $\mathrm{C}$ at $529.7 \mathrm{eV}$ can be assigned to the oxygen atom $\mathrm{Ti}-\underline{\mathrm{O}}$ in the $\mathrm{TiO}_{2}$ lattice [31]. In the $\mathrm{C}$ 1s spectrum, the three main characteristic $C$ 1s peaks $A, B$ and $C$ for PET are still well defined. In addition, a new peak $\mathrm{D}$ at $287.5 \mathrm{eV}$ is observed, which could possibly be due to the organic additives on the $\mathrm{TiO}_{2}$ surface [29]. 

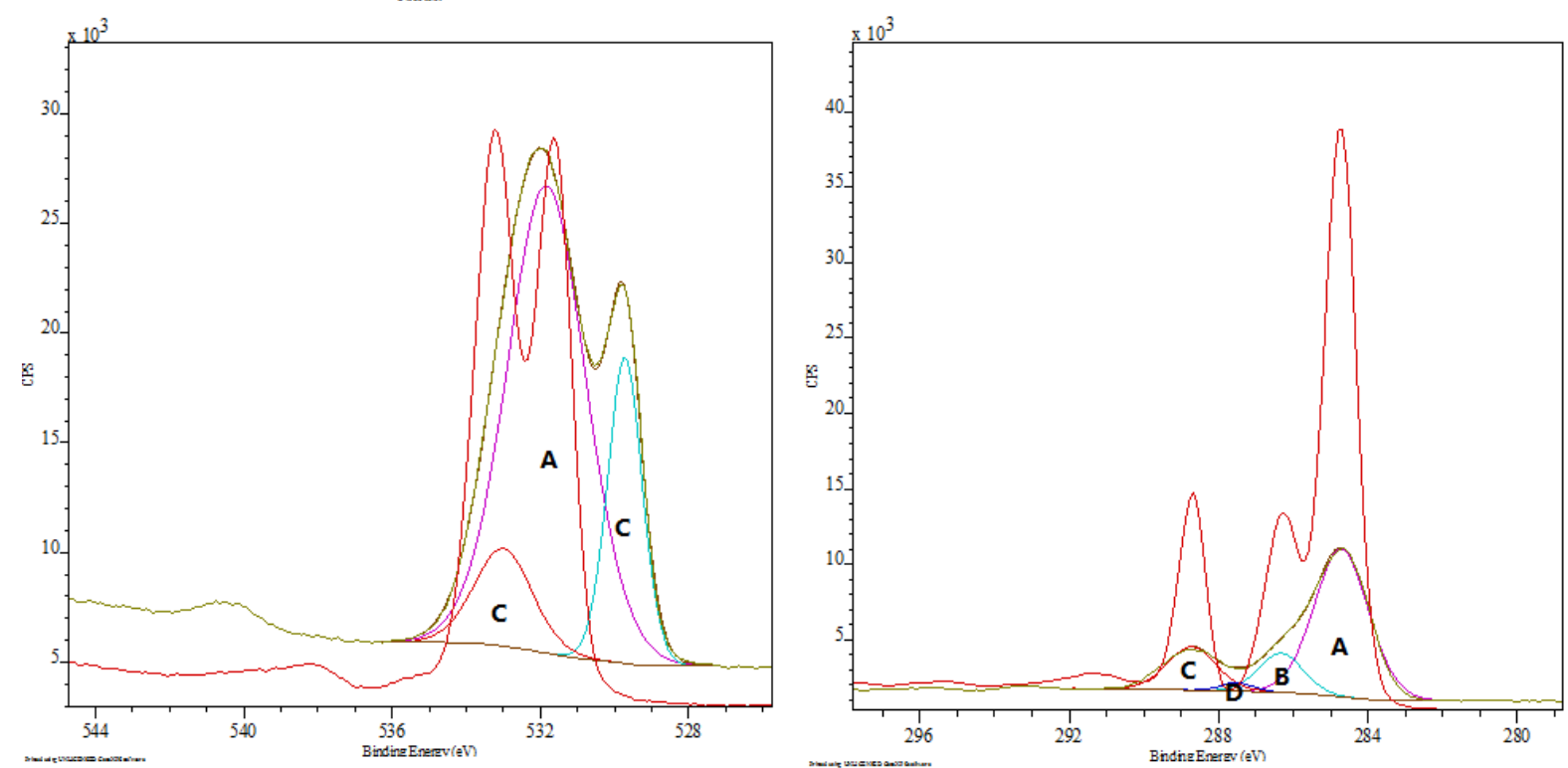

Figure 9: Overlaid $\mathrm{O} 1 \mathrm{~s}$ (left) and $\mathrm{C} 1 \mathrm{~s}$ (right) XPS spectra of $\mathrm{PET}^{-\mathrm{TiO}_{2}}$, before (red) and after (green) $\mathrm{PD}$ exposure, showing deconvolution (lettered curves)

\subsection{SEM analysis}

SEM images of untreated and PD exposed PET samples with inorganic fillers are illustrated in Figure 10. The surface condition of the untreated and PD exposed PET films are shown in Fig. 10(A) and (B), respectively, and not much change could be found between the two samples as expected. Fig. 10(C) and (D) represent the surface of untreated and PD exposed PET films filled with $\mathrm{BaSO}_{4}$, respectively. The filler 'pile-up' phenomenon can be directly observed. The filler particles dominate the PET resin in the PD affected area, forming a thin filler layer on the resin surface after PD erosion. 

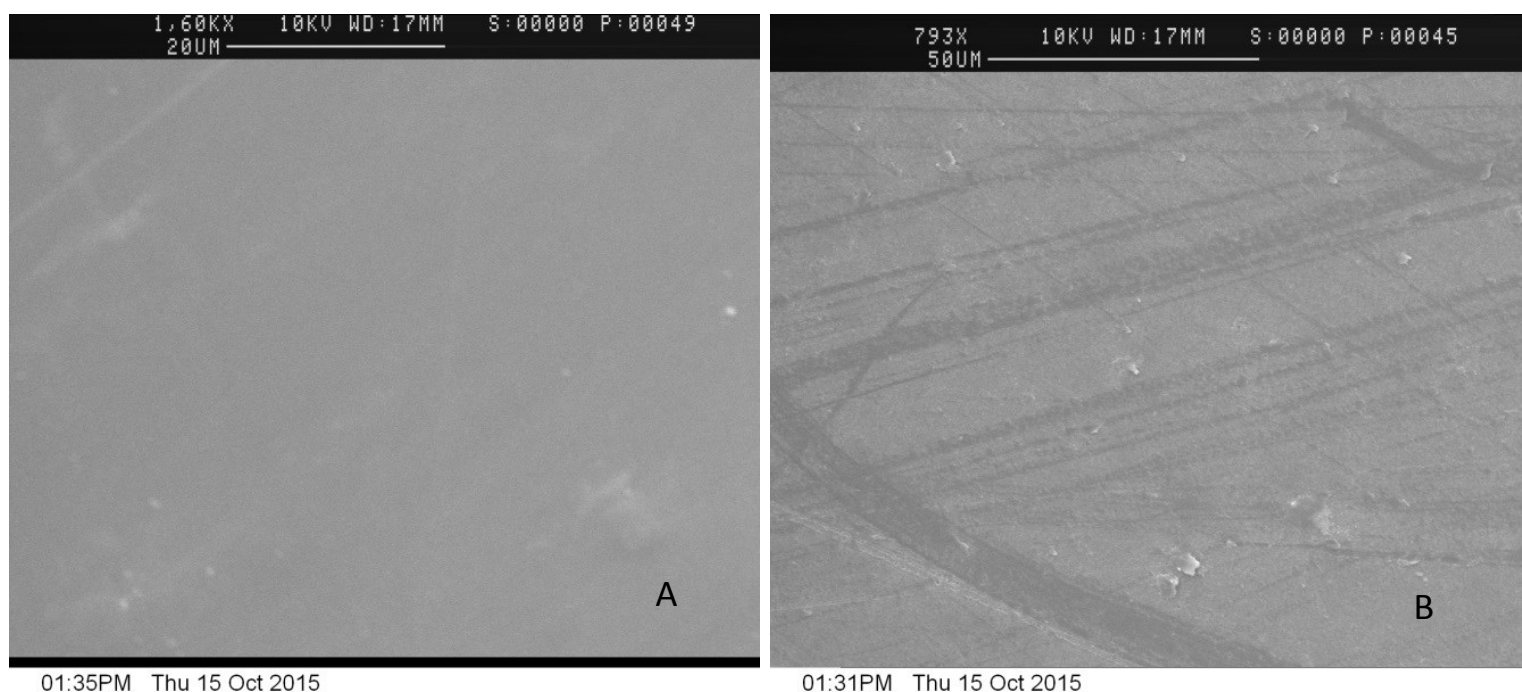

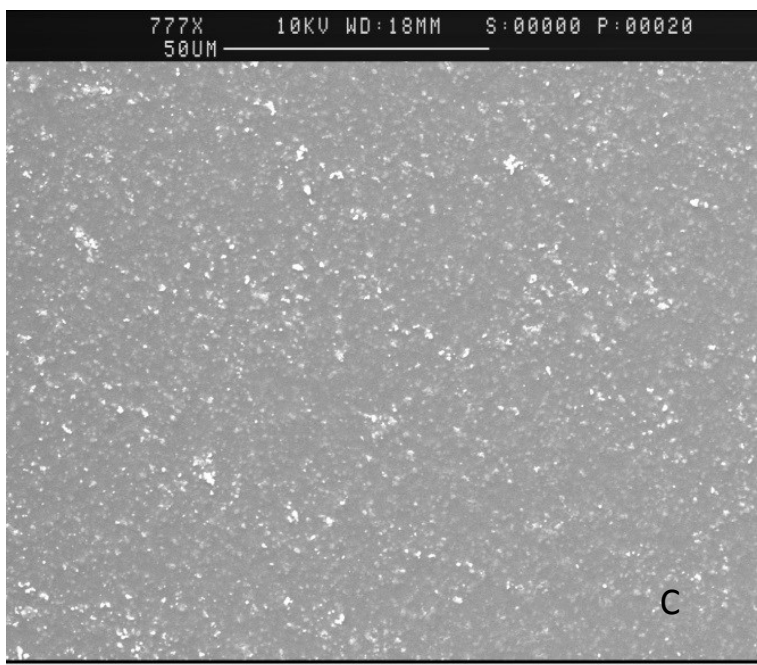

12:41PM Thu 15 Oct 2015

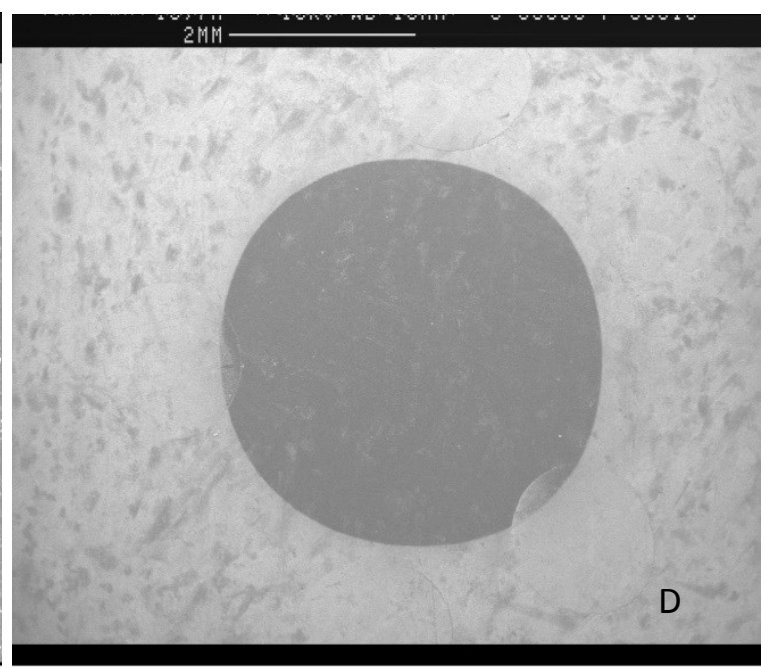

12:37PM Thu 15 Oct 2015

Figure 10: Untreated PET (A); PD exposed PET (B); untreated PET filled with $\mathrm{BaSO}_{4}(\mathrm{C})$; PD exposed PET filled with $\mathrm{BaSO}_{4}(\mathrm{D})$. The circle in the centre of $(\mathrm{D})$ is the shadow of the electrode.

\subsection{Discussion}

PD degradation and breakdown experiments of PET with and without different performance additives were carried out in this project. From Table 1, one can see that the three samples filled with inorganic particles, namely, PET-BaSO, $\mathrm{PET}-\mathrm{BaSO}_{4}-\mathrm{UV}$ and $\mathrm{PET}-\mathrm{TiO}_{2}$ have nearly identical PD erosion depths and that their erosion depths are much less than that the PET under all PD exposure conditions. The excellent PD resistances of these particlefilled films can be explained by the mechanisms that have been established for similar composites in the literature [3]. Since the fillers were physically blended with the PET resin in the extruder during the manufacturing process, it is reasonable to assume that no chemical coupling will occur between the fillers and PET resin. FTIR data confirm this 
assumption by showing that apart from the characteristic absorption bands of inorganic particles themselves no other peak shift or change can be observed for either PET-BaSO 4 (PET-BaSO $\left.{ }_{4}-\mathrm{UV}\right)$ or PET-TiO ${ }_{2}$. Indeed the effect of $\mathrm{BaSO}_{4}$ as a whitening agent relies explicitly on void formation at the polymer-particle interface.

The filler 'pile-up' phenomenon has been directly observed by different analytical methods. A schematic of the effect is shown in Figure 11. The inorganic fillers will remain on the eroded sample surface forming a protective layer. Due to the excellent PD resistance of the inorganic fillers this protective layer will not only significantly reduce the PD erosion rate but also inhibit oxygen from entering the unaffected region, which, in turn, will also reduce the degradation process. Furthermore, since the PET resin is three-dimensionally segmented by the well dispersed fillers, high energy ion bombardment will be partially blocked by these fillers which will decrease the erosion rate. This is the so called 'filler-segmentation' effect [32]. In addition, PD will concentrate more on the PD resistive inorganic fillers than the polymer resin because the permittivity of the fillers is higher than that of the polymer, causing the intensification of electric field around the inorganic fillers. In this case, the permittivity of PET resin, $\mathrm{BaSO}_{4}$ and $\mathrm{TiO}_{2}$ are 3.3, 11.5 and 110, respectively. Hence PD will concentrate even more on the fillers when the PET is filled with $\mathrm{TiO}_{2}$ than $\mathrm{BaSO}_{4}$. This can partially

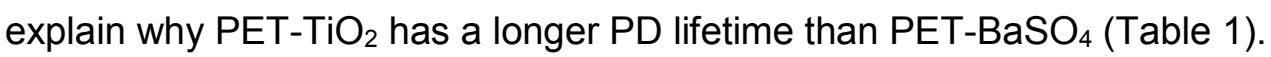

When polymer surface is subjected to PD, the sample surface will be bombarded by high energy ions such as electrons and positively charged particles that are generated by the avalanche breakdown of the air, leading to chemical bond cleavage and thus molecular mass decrease. What is more, the temperature of the PD activated region can easily rise to a few hundred ${ }^{\circ} \mathrm{C}$ and even beyond $1000^{\circ} \mathrm{C}$ for very short periods [3]. These high temperatures will undoubtedly cause local melting and decomposition of the material. Primary and secondary excited molecules such as activated oxygen and ozone, as well as UV radiation generated by PD will also chemically degrade the sample surface. All the above mentioned processes will gradually erode the sample surface and decrease the sample thickness and continuous decrease of the sample thickness will lead to the formation of pits (Figure 11). Once pits are produced, electric field will be greatly intensified in these regions and eventually electrical trees can be initiated from the bottom of the pits. These electrical trees will propagate toward the ground electrode which can cause the final breakdown of the polymer. The whole process is illustrated in Figure 12. The well dispersed particles inside the polymer are considered to be able to block the electrical tree propagation paths, thus enhancing the PD lifetime of the sample, as shown in Figure 11. It should be noted that the environments around the particles could play an important role in electrical tree propagation. $\mathrm{TiO}_{2}$, whose refractive index is higher than that of any other commercial fillers, is usually 
used as a whitener by a purely filler effect. On the other hand, $\mathrm{BaSO}_{4}$ is usually used as a void initiator during orientation to increase the light scattering and toughness of the polymer [33]. Therefore, it is reasonable to believe that more voids and defects will be present around $\mathrm{BaSO}_{4}$ than $\mathrm{TiO}_{2}$ when they are both used as fillers for PET. Electrical tree propagation will accelerate when a tree tip reaches the defects around $\mathrm{BaSO}_{4}$ and speed up the whole breakdown process; this is the main reason why $\mathrm{PET}-\mathrm{TiO}_{2}$ has a superior PD lifetime to $\mathrm{PET}-\mathrm{BaSO}_{4}$. PET-BaSO 4 -UV has the longest PD lifetime among the three filler-containing films. XPS results (Table 2) have shown that sample surface oxidation is less severe for PET-BaSO 4 -UV than PET-BaSO ${ }_{4}$, suggesting chemical degradation caused by primary and secondary excited molecules as well as UV radiation during PD erosion can be inhibited by the Tinuvin 1577 UV stabilizer for PET-BaSO ${ }_{4}$ UV (as illustrated on the right paths in Figure 12). Hence PD resistance and lifetime of the sample can be enhanced.

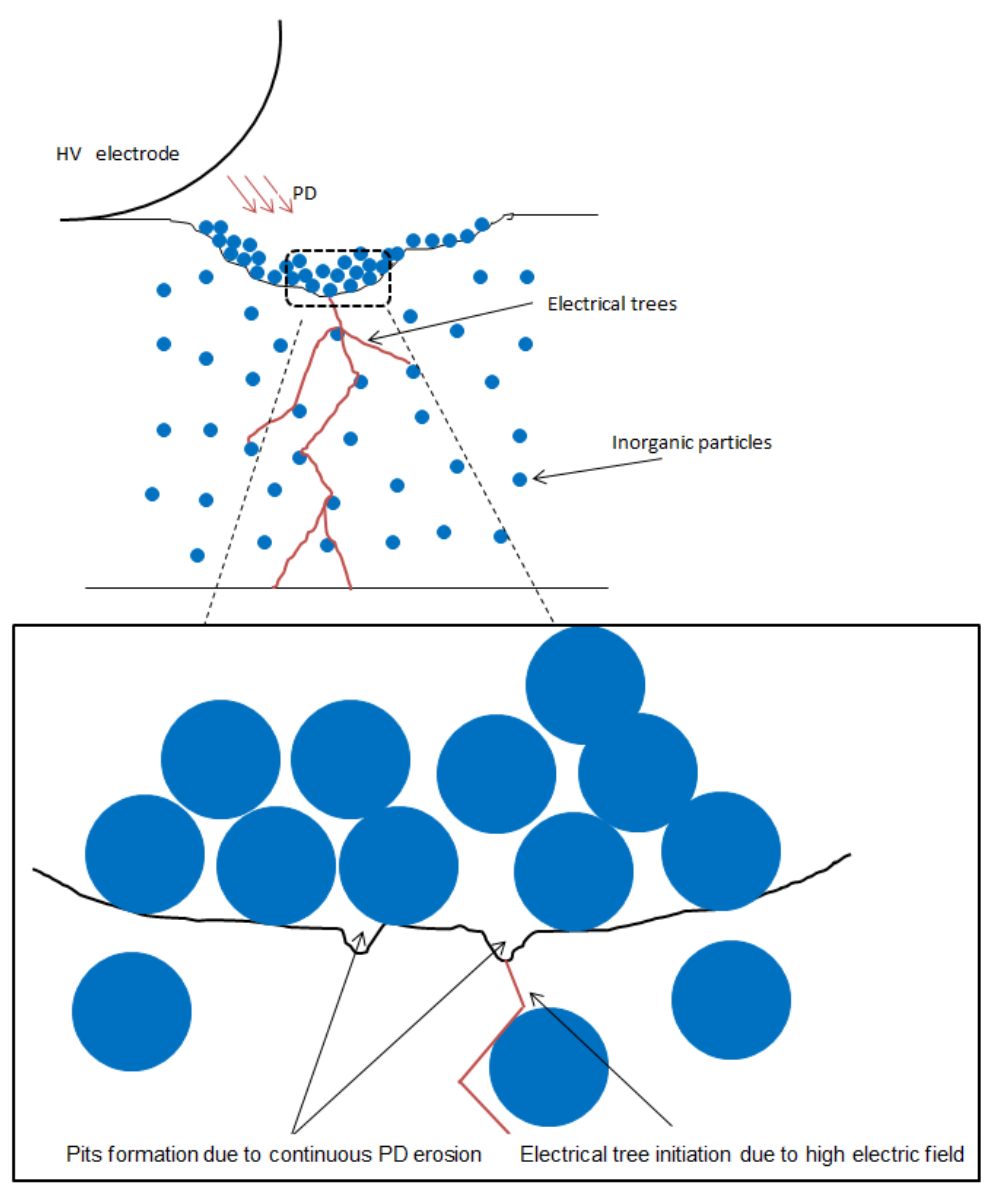

Figure 11: 'Pile-up' effect of fillers and dielectric breakdown caused by PD-initiated electrical tree 


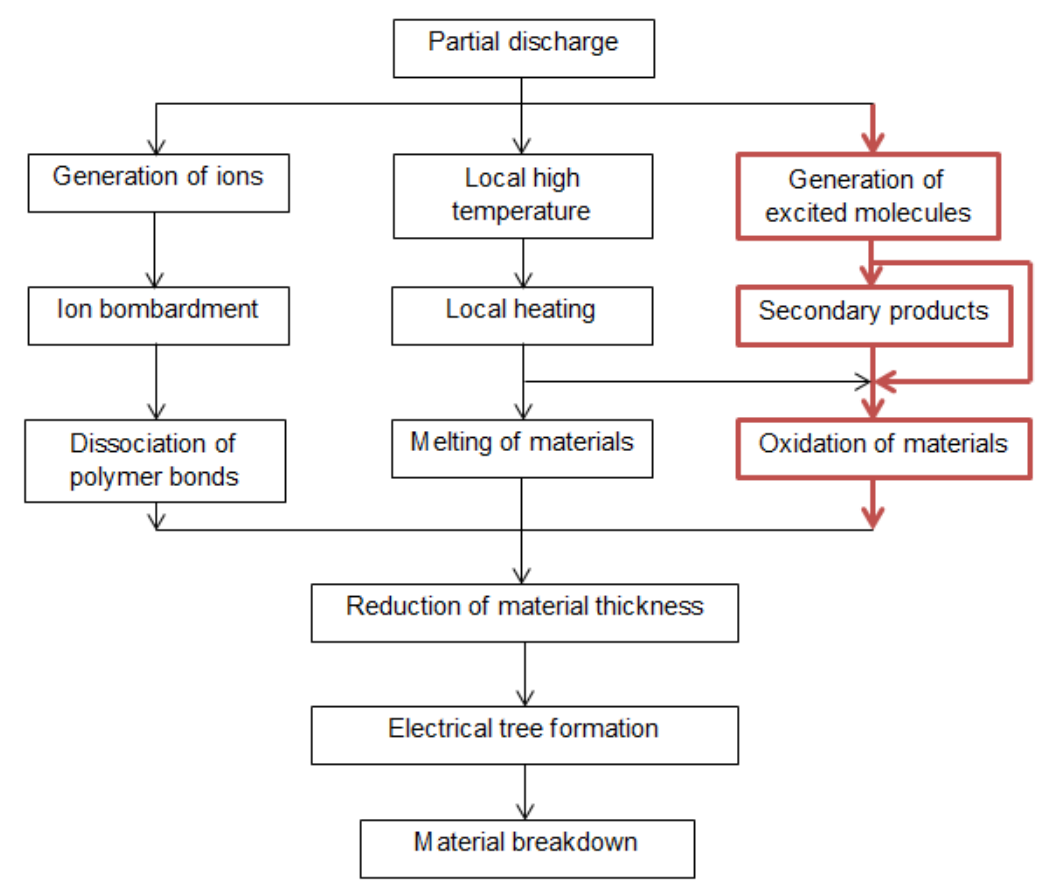

Figure 12: Physicochemical processes of polymer surface degradation caused by partial discharge [3]

\section{Conclusions}

Four categories of biaxially-oriented, semicrystalline PET films filled with different fillers and performance additives, namely, PET without any additive (pure PET), PET filled with $\mathrm{TiO}_{2}$ particles $\left(\mathrm{PET}-\mathrm{TiO}_{2}\right)$, PET filled with $\mathrm{BaSO}_{4}$ particles without and with Tinuvin $1577 \mathrm{UV}$

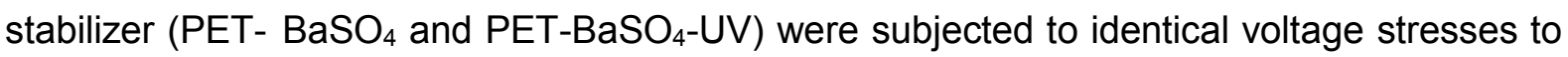
investigate the effect of fillers and additives on PD degradation and breakdown of PET films used in PV devices. Surface chemistry changes have been studied using ATR-FTIR and XPS techniques, and in each case, ester bond cleavage and surface oxidation were observed for the unfilled PET samples. On the other hand, for the inorganic filled samples, the filler 'pile-up' effect was directly observed after PD degradation. This is the main reason for the better PD resistance and PD lifetime of these samples. Dielectric breakdown results revealed that $\mathrm{PET}-\mathrm{TiO}_{2}$ has a $\mathrm{PD}$ lifetime superior to that of $\mathrm{PET}-\mathrm{BaSO}_{4}$, which could be attributed to the higher permittivity of the $\mathrm{TiO}_{2}$ fillers and the defects that were created around the $\mathrm{BaSO}_{4}$ particles during the orientation process. Further improvements on PD resistance and PD lifetime can be made if the particle-filled sample additionally incorporates 
a UV stabilizer that reduces the sample surface oxidation caused by PD, as has been quantitatively studied by the XPS technique. 


\section{References}

[1] Phillips, N.H., Givot, B., O'Brien, B., Korba, G. and Loyd, J., 2012, June. Analytical techniques used to determine chemical degradation of polymeric materials used in $\mathrm{PV}$ modules after sustained exposure to partial discharge voltages. In Photovoltaic Specialists Conference (PVSC), 2012 38th IEEE (pp. 000714-000719). IEEE.

[2] Kuffel, J. and Kuffel, P., 2000. High voltage engineering fundamentals. Newnes.

[3] Tanaka, T. and lizuka, T., 2010, October. Generic PD resistance characteristics of polymer nanocomposites. In Electrical Insulation and Dielectric Phenomena (CEIDP), 2010 Annual Report Conference on (pp. 1-4). IEEE.

[4] O'Hare, L.A., Smith, J.A., Leadley, S.R., Parbhoo, B., Goodwin, A.J. and Watts, J.F., 2002. Surface physico-chemistry of corona-discharge-treated poly(ethylene terephthalate) film. Surface and interface analysis, 33(7), pp.617-625.

[5] Pandiyaraj, K.N., Selvarajan, V., Deshmukh, R.R. and Bousmina, M., 2008. The effect of glow discharge plasma on the surface properties of poly(ethylene terephthalate)(PET) film. Surface and Coatings Technology, 202(17), pp.4218-4226.

[6] Ding, L., Shao, L. and Bai, Y., 2014. Deciphering the mechanism of corona discharge treatment of BOPET film. RSC Advances, 4(42), pp.21782-21787.

[7] Vitellas, I., Theodosiou, K., Gialas, I. and Agoris, D.P., 2005. Mechanism of degradation and breakdown in PET films under high intensity AC fields. The European Physical Journal Applied Physics, 30(2), pp.83-89.

[8] Kozako, M., Fuse, N., Ohki, Y., Okamoto, T. and Tanaka, T., 2004. Surface degradation of polyamide nanocomposites caused by partial discharges using IEC (b) electrodes. IEEE Transactions on Dielectrics and Electrical Insulation, 11(5), pp.833-839.

[9] Tanaka, T., Montanari, G.C. and Mulhaupt, R., 2004. Polymer nanocomposites as dielectrics and electrical insulation-perspectives for processing technologies, material characterization and future applications. IEEE Transactions on Dielectrics and Electrical Insulation, 11(5), pp.763-784.

[10] Tanaka, T., Ohki, Y., Ochi, M., Harada, M. and Imai, T., 2008. Enhanced partial discharge resistance of epoxy/clay nanocomposite prepared by newly developed organic 
modification and solubilization methods. IEEE Transactions on Dielectrics and Electrical Insulation, 15(1), pp.81-89.

[11] Li, Z., Okamoto, K., Ohki, Y. and Tanaka, T., 2010. Effects of nano-filler addition on partial discharge resistance and dielectric breakdown strength of Micro-Al 2 O 3 Epoxy composite. IEEE Transactions on Dielectrics and Electrical Insulation, 17(3), pp.653-661.

[12] Maity, P., Basu, S., Parameswaran, V. and Gupta, N., 2008. Degradation of polymer dielectrics with nanometric metal-oxide fillers due to surface discharges. IEEE Transactions on Dielectrics and Electrical Insulation, 15(1), pp.52-62.

[13] Maity, P., Kasisomayajula, S.V., Parameswaran, V., Basu, S. and Gupta, N., 2008. Improvement in surface degradation properties of polymer composites due to pre-processed nanometric alumina fillers. IEEE Transactions on Dielectrics and Electrical Insulation, 15(1), pp.63-72.

[14] Tanaka, T., Matsuo, Y. and Uchida, K., 2008, October. Partial discharge endurance of epoxy/SiC nanocomposite. In 2008 Annual Report Conference on Electrical Insulation and Dielectric Phenomena (pp. 13-16). IEEE.

[15] Zhao, X., Yin, J.H., Jin, R. and Dong, J.Y., 2013. Effect of Content and Layer Thickness on the Corona-Resistance of PI/TiO2 Nanocomposite Films. In Applied Mechanics and Materials (Vol. 395, pp. 133-137). Trans Tech Publications.

[16] Liang, C.Y. and Krimm, S., 1959. Infrared spectra of high polymers: Part IX. Polyethylene terephthalate. Journal of molecular spectroscopy, 3(1), pp.554-574.

[17] Grime, D. and Ward, I.M., 1958. The assignment of infra-red absorptions and rotational isomerism in polyethylene terephthalate and related compounds. Transactions of the Faraday Society, 54, pp.959-971.

[18] Chen, Z., 2013. The crystallization of poly(ethylene terephthalate) studied by thermal analysis and FTIR spectroscopy (Doctoral dissertation, University of Birmingham).

[19] Hollauer, E., Mondragon, M.A. and Castaño, V.M., 2001. Fourier transform infrared and Raman spectra, vibrational assignment and ab initio calculations of terephthalic acid and related compounds. Spectrochimica Acta Part A: Molecular and Biomolecular Spectroscopy, 57(5), pp.993-1007.

[20] Dowling, D.P., Tynan, J., Ward, P., Hynes, A.M., Cullen, J. and Byrne, G., 2012. Atmospheric pressure plasma treatment of amorphous polyethylene terephthalate for 
enhanced heatsealing properties. International Journal of Adhesion and Adhesives, 35, pp.1-8.

[21] Ramaswamy, V., Vimalathithan, R.M. and Ponnusamy, V., 2010. Synthesis and characterization of BaSO4 nano particles using micro emulsion technique. Adv. Appl. Sci. Res, 1(3), pp.197-204.

[22] Zheng, Z., Liu, B.W., Ting Yang, S., Cui, X. and Wang, H., 2015. Preparation of a novel phosphorus-and nitrogen-containing flame retardant and its synergistic effect in the intumescent flame-retarding polypropylene system. Polymer Composites, 36(9), pp.16061619.

[23] Bottino, F.A., Di Pasquale, G., Pollicino, A., Recca, A., 1998. Surface photostabilization of polystyrene by Tinuvin 1577, Journal of Applied Polymer Science, 69, 1251-1256.

[24] Schmitz, P.J., 2001. Characterization of the Surface of BaSO4 Powder by XPS. Surface Science Spectra, 8(3), pp.195-199.

[25] Lai, B. and Ni, X., 2008. Rheological Behaviour and Interaction of Polycarbonate/Barium Sulfate Composites. Journal of Macromolecular Science, Part B, 47(5), pp.1028-1038.

[26] Jerndal, E., Mattisson, T. and Lyngfelt, A., 2006. Thermal analysis of chemical-looping combustion. Chemical Engineering Research and Design, 84(9), pp.795-806.

[27] Majjane, A., Chahine, A., Et-tabirou, M., Echchahed, B., Do, T.O. and Mc Breen, P., 2014. X-ray photoelectron spectroscopy (XPS) and FTIR studies of vanadium barium phosphate glasses. Materials Chemistry and Physics, 143(2), pp.779-787.

[28] Jensen, H., Soloviev, A., Li, Z. and Søgaard, E.G., 2005. XPS and FTIR investigation of the surface properties of different prepared titania nano-powders. Applied Surface Science, 246(1), pp.239-249.

[29] Rothon, R. ed., 2003. Particulate-filled polymer composites. iSmithers Rapra Publishing.

[30] Todea, M., Vanea, E., Bran, S., Berce, P. and Simon, S., 2013. XPS analysis of aluminosilicate microspheres bioactivity tested in vitro. Applied Surface Science, 270, pp.777-783.

[31] Salarian, M., Xu, W.Z., Biesinger, M.C. and Charpentier, P.A., 2014. Synthesis and characterization of novel TiO 2-poly(propylene fumarate) nanocomposites for bone cementation. Journal of Materials Chemistry B, 2(32), pp.5145-5156. 
[32] Tanaka, T., 2009, July. Similarity between treeing lifetime and PD resistance in aging mechanisms for epoxy nanocomposites. In 2009 IEEE 9th International Conference on the Properties and Applications of Dielectric Materials (pp. 741-744). IEEE.

[33] Wu, H. and Cao, Y.M., 2012. A study of polyvinyl chloride modified by barium sulfate. In Applied Mechanics and Materials (Vol. 117, pp. 1402-1405). Trans Tech Publications. 